\title{
Coupled points in ordered generalized metric spaces and application to integro-differential equations
}

\author{
Nguyen Van Luong and Nguyen Xuan Thuan
}

\begin{abstract}
In this paper, we prove some coupled fixed point theorems for $O$ compatible mappings in partially ordered generalized metric spaces under certain conditions to extend and complement the recent fixed point theorems due to Bhaskar and Lakshmikantham [Nonlinear Anal. TMA 65 (2006) 1379 - 1393] and Berinde [Nonlinear Anal. TMA 74 (2011) 7347-7355]. We give some examples to illustrate our results. An application to integro-differential equations is also given.
\end{abstract}

\section{Introduction and preliminaries}

Let $(X, d)$ be a metric space. A mapping $T: X \rightarrow X$ is called a contraction mapping if there exists a $k \in[0,1)$ such that

$$
d(T x, T y) \leq k d(x, y), \quad \text { for all } x, y \in X .
$$

The well-known Banach contraction principle states that a contraction mapping of a complete metric space into itself has a unique fixed point. This celebrated principle is one of the pivotal results of analysis and has applications in a number of branches of mathematics. The above principle has been

Key Words: Coupled coincidence point; Coupled fixed point; Mixed monotone property; $O$-compatible mappings; integro-differential equations.

2010 Mathematics Subject Classification: Primary 54H25; Secondary 47H10.

Received: January, 2012

Revised: May, 2012.

Accepted: March, 2013. 
extended and generalized in various directions for recent years by putting conditions on the mappings or on the spaces.

In [28], Perov extended the Banach contraction principle for contraction mappings on spaces endowed with vector-valued metrics, namely generalized metric spaces. The notion of a generalized metric space is stated as follows

Definition 1.1. ([28]) Let $X$ be non-empty set and $N \geq 1$. A mapping $d: X \times X \rightarrow \mathbb{R}^{N}$ is said to be a generalized metric on $X$ if the following conditions are satisfied:

(i) $d(x, y) \geq \theta$, for all $x, y \in X$ and $d(x, y)=\theta$ if and only if $x=y$,

(ii) $d(x, y)=d(y, x)$, for all $x, y \in X$,

(iii) $d(x, y) \leq d(x, z)+d(z, y)$, for all $x, y, z \in X$.

$A$ set $X$ equipped with a generalized metric $d$ is called a generalized metric space. We will denote such a space by $(X, d)$. Here, the order relation on $\mathbb{R}^{N}$ is defined by, for $x=\left(x_{1}, x_{2}, \ldots, x_{N}\right), y=\left(y_{1}, y_{2}, \ldots, y_{N}\right) \in \mathbb{R}^{N}$,

$$
x \leq y \Leftrightarrow x_{i} \leq y_{i} \text { in } \mathbb{R}, \text { for all } i=1,2, \ldots, N .
$$

Notice that a generalized metric space is a usual metric space when $N=1$.

For generalized metric spaces, the notions of convergent sequences, Cauchy sequences, completeness, open subsets, closed subsets and continuous mappings are similar to those for usual metric spaces.

Throughout this paper we denote by $M_{N}\left(\mathbb{R}_{+}\right)$the set of all $N \times N$ matrices with positive elements, by $\Theta$ the zero matrix, by $I$ the identity matrix and by $\theta$ the zero element of $\mathbb{R}^{N}$. Notice also that, for the sake of simplicity, we will make an identication between row and column vectors in $\mathbb{R}^{N}$.

Recall that a matrix $A$ is said to be convergent to zero if and only if $A^{n} \rightarrow \Theta$ as $n \rightarrow \infty$ (see [37]). For the proof of the main result we need the following Lemma (see [37], [32], [30])

Lemma 1.2. Let $A \in M_{N}\left(\mathbb{R}_{+}\right)$. The following statements are equivalent:

(i) A converges to zero.

(ii) $A^{n} \rightarrow \Theta$ as $n \rightarrow \infty$.

(iii) The eigenvalues of $A$ are in the open unique disk i.e.

$$
\rho(A)=\max \{|\lambda|: \lambda \in \mathbb{C} \text { with } \operatorname{det}(A-\lambda I)=0\}<1 .
$$

(iv) The matrix $I-A$ is non-singular and

$$
(I-A)^{-1}=I+A+A^{2}+\ldots+A^{n}+\ldots
$$


(v) The matrix $I-A$ is non-singular and $(I-A)^{-1}$ has non-negative elements.

(vi) $A^{n} q \rightarrow \theta$ and $q A^{n} \rightarrow \theta$ as $n \rightarrow \infty$ for all $q \in \mathbb{R}^{N}$.

For examples and considerations on matrices which converge to zero, see Bica and Muresan [8], Rus [32], Turinici [31] and so on.

The main result for contraction mappings on generalized metric spaces is the Perov's fixed point theorem.

Theorem 1.3. ([28]) Let $(X, d)$ be a complete generalized metric space such that $d(x, y) \in \mathbb{R}^{N}, N \geq 1$, for all $x, y \in X$. Let $T: X \rightarrow X$ and suppose there exists a matrix $A \in M_{N}\left(\mathbb{R}_{+}\right)$such that

$$
d(T x, T y) \leq A d(x, y), \quad \forall x, y \in X .
$$

If $A$ converges to zero, then

(i) Thas a unique fixed point,

(ii) the sequence of successive approximations $\left\{x_{n}\right\}, x_{n}=T x_{n-1}$ is convergent and it has the limit $x^{*}$, for all $x_{0} \in X$,

(iii) one has the following estimate

$$
d\left(x_{n}, x^{*}\right) \leq A^{n}(I-A)^{-1} d\left(x_{0}, x_{1}\right) .
$$

For some extensions and applications of the Perov's fixed point theorem, one can see in [7]-[9], [13], [24], [29], [30], [26], [31], [38] and references therein.

Recently, existence of fixed points for contraction type mappings in partially ordered metric spaces has been considered in [1] - [6], [10] - [12], [14] [24], [33] - [36] and references therein, where some applications to matrix equations, ordinary differential equations, and integral equations were presented. Bhaskar and Lakshmikantham [6] introduced notions of mixed monotone mappings and coupled fixed points and proved some coupled fixed point theorems for the mixed monotone mappings and discussed the existence and uniqueness of solutions for periodic boundary value problems.

Definition 1.4. ([6]) Let $(X, \preceq)$ be a partially ordered set and $F: X \times X \rightarrow$ $X$. The mapping $F$ is said to have the mixed monotone property if $F(x, y)$ is monotone non-decreasing in $x$ and is monotone non-increasing in $y$, that is, for any $x, y \in X$,

$$
x_{1}, x_{2} \in X, \quad x_{1} \preceq x_{2} \Rightarrow F\left(x_{1}, y\right) \preceq F\left(x_{2}, y\right),
$$

and

$$
y_{1}, y_{2} \in X, \quad y_{1} \preceq y_{2} \Rightarrow F\left(x, y_{1}\right) \succeq F\left(x, y_{2}\right) .
$$


Definition 1.5. ([6]) An element $(x, y) \in X \times X$ is called a coupled fixed point of the mapping $F: X \times X \rightarrow X$ if

$$
F(x, y)=x, \text { and } F(y, x)=y .
$$

Theorem 1.6. ([6]) Let $(X, \preceq)$ be a partially ordered set and suppose there exists a metric $d$ on $X$ such that $(X, d)$ is a complete metric space. Let $F$ : $X \times X \rightarrow X$ be a continuous mapping having the mixed monotone property on $X$. Assume that there exists a $k \in[0,1)$ with

$$
d(F(x, y), F(u, v)) \leq \frac{k}{2}[d(x, u)+d(y, v)], \text { for each } x \succeq u \text { and } y \preceq v .
$$

If there exist $x_{0}, y_{0} \in X$ such that

$$
x_{0} \preceq F\left(x_{0}, y_{0}\right) \text { and } y_{0} \succeq F\left(y_{0}, x_{0}\right),
$$

then there exist $x, y \in X$ such that

$$
x=F(x, y) \text { and } y=F(y, x) .
$$

Theorem 1.7. ([6]) Let $(X, \preceq)$ be a partially ordered set and suppose there exists a metric $d$ on $X$ such that $(X, d)$ is a complete metric space. Assume that $X$ has the following property:

(i) if a non-decreasing sequence $\left\{x_{n}\right\} \rightarrow x$, then $x_{n} \preceq x$ for all $n$,

(ii) if a non-increasing sequence $\left\{y_{n}\right\} \rightarrow y$, then $y \preceq y_{n}$ for all $n$.

Let $F: X \times X \rightarrow X$ be a continuous mapping having the mixed monotone property on $X$. Assume that there exists a $k \in[0,1)$ with

$$
d(F(x, y), F(u, v)) \leq \frac{k}{2}[d(x, u)+d(y, v)], \text { for each } x \succeq u \text { and } y \preceq v .
$$

If there exist $x_{0}, y_{0} \in X$ such that

$$
x_{0} \preceq F\left(x_{0}, y_{0}\right) \text { and } y_{0} \succeq F\left(y_{0}, x_{0}\right),
$$

then there exist $x, y \in X$ such that

$$
x=F(x, y) \text { and } y=F(y, x) .
$$

Afterward, coupled fixed points for mappings having mixed monotone property were established in various partially ordered spaces such as metric spaces, cone metric spaces, $G$ - metric spaces, partial metric spaces (see 
[4], [5], [6], [10], [11], [14], [17], [18] - [20], [34] - [36] and references therein). In particular, Lakshmikantham and Ciric [18] established coupled coincidence and coupled fixed point theorems for two mappings $F: X \times X \rightarrow X$ and $g: X \rightarrow X$, where $F$ has the mixed $g$-monotone property and the functions $F$ and $g$ commute, as an extension of the coupled fixed point results in [6].

Later, Choudhury and Kundu in [10] introduced the concept of compatibility and proved the result established in [18] under a different set of conditions. Precisely, they established their result by assuming that $F$ and $g$ are compatible mappings and the function $g$ is monotone increasing.

Definition 1.8. ([18]) Let $(X, \preceq)$ be a partially ordered set and let $F$ : $X \times X \rightarrow X$ and $g: X \rightarrow X$ are two mappings. We say $F$ has the mixed $g$-monotone property if $F(x, y)$ is $g$ - non-decreasing in its first argument and is $g$-non-increasing in its second argument, that is, for any $x, y \in X$,

$$
x_{1}, x_{2} \in X, \quad g x_{1} \preceq g x_{2} \Rightarrow F\left(x_{1}, y\right) \preceq F\left(x_{2}, y\right),
$$

and

$$
y_{1}, y_{2} \in X, \quad g y_{1} \preceq g y_{2} \Rightarrow F\left(x, y_{1}\right) \succeq F\left(x, y_{2}\right) .
$$

Definition 1.9. ([18]) An element $(x, y) \in X \times X$ is called a coupled coincident point of the mapping $F: X \times X \rightarrow X$ and $g: X \rightarrow X$ if

$$
g x=F(x, y) \text { and } g y=F(y, x) .
$$

Definition 1.10. ([10]) Let $(X, d)$ be a metric space. The mappings $F$ and $g$, where $F: X \times X \rightarrow X, g: X \rightarrow X$, are said to be compatible if

$$
\lim _{n \rightarrow \infty} d\left(g F\left(x_{n}, y_{n}\right), F\left(g x_{n}, g y_{n}\right)\right)=0,
$$

and

$$
\lim _{n \rightarrow \infty} d\left(g F\left(y_{n}, x_{n}\right), F\left(g y_{n}, g x_{n}\right)\right)=0,
$$

where $\left\{x_{n}\right\}$ and $\left\{y_{n}\right\}$ are sequences in $X$ such that $\lim _{n \rightarrow \infty} F\left(x_{n}, y_{n}\right)$ $=\lim _{n \rightarrow \infty} g x_{n}=x$ and $\lim _{n \rightarrow \infty} F\left(y_{n}, x_{n}\right)=\lim _{n \rightarrow \infty} g y_{n}=y$ for all $x, y \in X$ are satisfied.

Very recently, Berinde [5], in his interesting paper, extended the coupled fixed point theorems for mixed monotone mappings obtained by Bhaskar and Lakshmikantham [6] by significantly weakening the contractive condition involved and gave an application to periodic boundary value problems. His main result is the following theorem 
Theorem 1.11. ([5]) Let $(X, \preceq)$ be a partial generalized ordered set and suppose there is a metric $d$ on $X$ such that $(X, d)$ is a complete metric space. Let $F: X \times X \rightarrow X$ be a mixed monotone mapping for which there exists a constant $k \in[0,1)$ such that for each $x \succeq u, y \preceq v$,

$$
d(F(x, y), F(u, v))+d(F(y, x), F(v, u)) \leq k[d(x, u)+d(y, v)] .
$$

If there exist $x_{0}, y_{0} \in X$ such that

$$
x_{0} \preceq F\left(x_{0}, y_{0}\right) \text { and } y_{0} \succeq F\left(y_{0}, x_{0}\right),
$$

or

$$
x_{0} \succeq F\left(x_{0}, y_{0}\right) \text { and } y_{0} \preceq F\left(y_{0}, x_{0}\right),
$$

then there exist $x, y \in X$ such that $x=F(x, y)$ and $y=F(y, x)$.

Inspired by the above results, in this paper, we first introduce a concept of $O$-compatible mappings in partially ordered generalized metric spaces. This concept is slightly more general than the concept of compatible mappings. Then we prove some coupled coincidence point and coupled fixed point theorems for mapping $F: X \times X \rightarrow X$ having the mixed $g$ - monotone property in partially ordered generalized metric spaces. The results extend and improve the results of Bhaskar and Lakshmikantham [6] and Berinde [5]. We also give some examples to illustrate our results. Moreover, an application to integro-differential equations is given.

Definition 1.12. Let $(X, d, \preceq)$ be a partially ordered generalized metric space. The mappings $F: X \times X \rightarrow X$ and $g: X \rightarrow X$ are said to be $O$ compatible if

$$
\lim _{n \rightarrow \infty} d\left(g F\left(x_{n}, y_{n}\right), F\left(g x_{n}, g y_{n}\right)\right)=0,
$$

and

$$
\lim _{n \rightarrow \infty} d\left(g F\left(y_{n}, x_{n}\right), F\left(g y_{n}, g x_{n}\right)\right)=0,
$$

where $\left\{x_{n}\right\}$ and $\left\{y_{n}\right\}$ are sequences in $X$ such that $\left\{g x_{n}\right\},\left\{g y_{n}\right\}$ are monotone and

$$
\lim _{n \rightarrow \infty} F\left(x_{n}, y_{n}\right)=\lim _{n \rightarrow \infty} g x_{n}=x,
$$

and

$$
\lim _{n \rightarrow \infty} F\left(y_{n}, x_{n}\right)=\lim _{n \rightarrow \infty} g y_{n}=y,
$$

for all $x, y \in X$ are satisfied.

Remark 1.13. Let $(X, d, \preceq)$ be a partially generalized metric space. If $F: X \times X \rightarrow X$ and $g: X \rightarrow X$ are compatible then they are $O$-compatible. However, the converse is not true. The following example shows that there exist mappings which are $O$-compatible but not compatible. 
Example 1.14. Let $X=\{0\} \cup[1 / 2,2]$ with the usual metric $d(x, y)=$ $|x-y|$, for all $x, y \in X$. We consider the following order relation on $X$

$$
x, y \in X \quad x \preceq y \Leftrightarrow x=y \text { or }(x, y)=(0,1) .
$$

Let $F: X \times X \rightarrow X$ be given by

$$
F(x, y)= \begin{cases}0 & \text { if } x, y \in\{0\} \cup[1 / 2,1] \\ 1 & \text { otherwise }\end{cases}
$$

and $g: X \rightarrow X$ be defined by

$$
g x= \begin{cases}0 & \text { if } x=0 \\ 1 & \text { if } 1 / 2 \leq x \leq 1 \\ 2-x & \text { if } 1<x \leq 3 / 2 \\ 1 / 2 & \text { if } 3 / 2<x \leq 2\end{cases}
$$

Then $F$ and $g$ are $O$-compatible. Indeed, let $\left\{x_{n}\right\},\left\{y_{n}\right\}$ in $X$ such that $\left\{g x_{n}\right\},\left\{g y_{n}\right\}$ are monotone and

$$
\lim _{n \rightarrow \infty} F\left(x_{n}, y_{n}\right)=\lim _{n \rightarrow \infty} g x_{n}=x,
$$

and

$$
\lim _{n \rightarrow \infty} F\left(y_{n}, x_{n}\right)=\lim _{n \rightarrow \infty} g y_{n}=y,
$$

for some $x, y \in X$. Since $F\left(x_{n}, y_{n}\right)=F\left(y_{n}, x_{n}\right) \in\{0,1\}$ for all $n, x=y \in$ $\{0,1\}$. The case $x=y=1$ is impossible. In fact, if $x=y=1$, then since $\left\{g x_{n}\right\},\left\{g y_{n}\right\}$ are monotone, $g x_{n}=g y_{n}=1$ for all $n \geq n_{1}$, for some $n_{1}$. That is $x_{n}, y_{n} \in[1 / 2,1]$ for all $n \geq n_{1}$. This implies $F\left(x_{n}, y_{n}\right)=F\left(y_{n}, x_{n}\right)=0$, for all $n \geq n_{1}$, which is a contradiction. Thus $x=y=0$. That implies $g x_{n}=g y_{n}=0$ for all $n \geq n_{2}$, for some $n_{2}$. That is $x_{n}=y_{n}=0$ for all $n \geq n_{2}$. Thus, for all $n \geq n_{2}$,

$$
d\left(g F\left(x_{n}, y_{n}\right), F\left(g x_{n}, g y_{n}\right)\right)=d\left(g F\left(y_{n}, x_{n}\right), F\left(g y_{n}, g x_{n}\right)\right)=0 .
$$

Hence

$$
\lim _{n \rightarrow \infty} d\left(g F\left(x_{n}, y_{n}\right), F\left(g x_{n}, g y_{n}\right)\right)=0
$$

and

$$
\lim _{n \rightarrow \infty} d\left(g F\left(y_{n}, x_{n}\right), F\left(g y_{n}, g x_{n}\right)\right)=0,
$$

hold. Therefore $F$ and $g$ are $O$-compatible.

However, $F$ and $g$ are not compatible. Indeed, let $\left\{x_{n}\right\},\left\{y_{n}\right\}$ in $X$ be defined by

$$
x_{n}=y_{n}=1+\frac{1}{n+1}, \quad n=1,2,3, . .
$$


We have

$$
F\left(x_{n}, y_{n}\right)=F\left(y_{n}, x_{n}\right)=F\left(1+\frac{1}{n+1}, 1+\frac{1}{n+1}\right)=1,
$$

and

$$
g x_{n}=g y_{n}=g\left(1+\frac{1}{n+1}\right)=1-\frac{1}{n+1} \rightarrow 1 \text { as } n \rightarrow \infty,
$$

but

$$
\begin{aligned}
d\left(g F\left(x_{n}, y_{n}\right), F\left(g x_{n}, g y_{n}\right)\right) & =d\left(F\left(1-\frac{1}{n+1}, 1-\frac{1}{n+1}\right), g 1\right) \\
& =d(0,1)=1 \nrightarrow 0 \text { as } n \rightarrow \infty .
\end{aligned}
$$

Thus, $F$ and $g$ are not compatible.

We are now going to prove our main results.

\section{Coupled point theorems}

Theorem 2.1. Let $(X, d, \preceq)$ be a partially ordered complete generalized metric space. Suppose $F: X \times X \rightarrow X$ and $g: X \rightarrow X$ are mappings such that $F$ has the mixed $g$ - monotone property. Assume that there exist $A, B \in M_{N}\left(\mathbb{R}_{+}\right)$with $\rho\left(\frac{1}{2}(A+B)\right)<1$ such that

$$
d(F(x, y), F(u, v))+d(F(y, x), F(v, u)) \leq A d(g x, g u)+B d(g y, g v),
$$

for all $x, y, u, v \in X$ with $g x \succeq g u$ and $g y \preceq g v$. Suppose $F(X \times X) \subseteq g(X)$, $g$ is continuous and $g$ is $O$-compatible with $F$. Suppose either

(a) F is continuous or

(b) X has the following property

(i) if a non-decreasing sequence $\left\{x_{n}\right\} \rightarrow x$, then $g x_{n} \preceq$ gx for all $n$,

(ii) if a non-increasing sequence $\left\{y_{n}\right\} \rightarrow y$, then gy $\preceq y_{n}$ for all $n$.

If there exist two elements $x_{0}, y_{0} \in X$ with

$$
g x_{0} \preceq F\left(x_{0}, y_{0}\right) \text { and } g y_{0} \succeq F\left(y_{0}, x_{0}\right),
$$

then $F$ and $g$ have a coupled coincidence point in $X$. 
Proof. Let $x_{0}, y_{0} \in X$ be such that $g x_{0} \preceq F\left(x_{0}, y_{0}\right)$ and $g y_{0} \succeq F\left(y_{0}, x_{0}\right)$. Since $F(X \times X) \subseteq g(X)$, we construct two sequences $\left\{x_{n}\right\}$ and $\left\{y_{n}\right\}$ in $X$ as follows

$$
g x_{n+1}=F\left(x_{n}, y_{n}\right) \text { and } g y_{n+1}=F\left(y_{n}, x_{n}\right), \text { for all } n \geq 0
$$

By the mixed $g$ - monotone property of $F$, using the mathematical induction, one can easily show that

$$
g x_{n} \preceq g x_{n+1},
$$

and

$$
g y_{n} \succeq g y_{n+1}
$$

for all $n \geq 0$.

Since $g x_{n} \succeq g x_{n-1}$ and $g y_{n} \preceq g y_{n-1}$, from (1) and (2), we have

$$
\begin{aligned}
d\left(g x_{n+1}, g x_{n}\right)+d\left(g y_{n+1}, g y_{n}\right)= & d\left(F\left(x_{n}, y_{n}\right), F\left(x_{n-1}, y_{n-1}\right)\right) \\
& +d\left(F\left(y_{n}, x_{n}\right), F\left(y_{n-1}, x_{n-1}\right)\right) \\
\leq & \left.A d\left(g x_{n}, g x_{n-1}\right)+B d\left(g y_{n}, g y_{n-1}\right)\right)
\end{aligned}
$$

Similarly, since $g y_{n-1} \succeq g y_{n}$ and $g x_{n-1} \preceq g x_{n}$,

$$
\begin{aligned}
d\left(g y_{n}, g y_{n+1}\right)+d\left(g x_{n}, g x_{n+1}\right)= & d\left(F\left(y_{n-1}, x_{n-1}\right), F\left(y_{n}, x_{n}\right)\right) \\
& +d\left(F\left(x_{n-1}, y_{n-1}\right), F\left(x_{n}, y_{n}\right)\right) \\
\leq & A d\left(g y_{n-1}, y_{n}\right)+B d\left(g x_{n-1}, g x_{n}\right)
\end{aligned}
$$

From (5) and (6), we have

$$
\left.d\left(g x_{n+1}, g x_{n}\right)+d\left(g y_{n+1}, g y_{n}\right) \leq \frac{1}{2}(A+B)\left[d\left(g x_{n}, g x_{n-1}\right)+d\left(g y_{n}, g y_{n-1}\right)\right)\right]
$$

Set $d_{n}=d\left(g x_{n+1}, g x_{n}\right)+d\left(g y_{n+1}, g y_{n}\right), M=\frac{1}{2}(A+B)$, then $M \in M_{N}\left(\mathbb{R}_{+}\right)$ and $\rho(M)<1$. From $(7)$, we have

$$
d_{n} \leq M d_{n-1} \leq M^{2} d_{n-2} \leq \ldots \leq M^{n} d_{0}
$$

Since $\rho(M)<1, M^{n} \rightarrow \Theta$ as $n \rightarrow \infty$. Taking the limits as $n \rightarrow \infty$ in (8), we get

$$
\lim _{n \rightarrow \infty} d_{n}=\lim _{n \rightarrow \infty}\left[d\left(g x_{n+1}, g x_{n}\right)+d\left(g y_{n+1}, g y_{n}\right)\right]=0
$$

For $m>n$, we have 


$$
\begin{aligned}
& d\left(g x_{m}, g x_{n}\right)+d\left(g y_{m}, g y_{n}\right) \\
& \leq \quad d\left(g x_{m}, g x_{m-1}\right)+d\left(g x_{m-1}, g x_{m-2}\right)+\ldots+d\left(g x_{n+1}, g x_{n}\right) \\
&+d\left(g y_{m}, g y_{m-1}\right)+d\left(g y_{m-1}, g y_{m-2}\right)+\ldots+d\left(g y_{n+1}, g y_{n}\right) \\
& \leq {\left[d\left(g x_{n+1}, g x_{n}\right)+d\left(g y_{n+1}, g y_{n}\right)\right]+\ldots+\left[d\left(g x_{m-1}, g x_{m-2}\right)\right.} \\
&\left.+d\left(g y_{m-1}, g y_{m-2}\right)\right]+\left[d\left(g x_{m}, g x_{m-1}\right)+d\left(g y_{m}, g y_{m-1}\right)\right]+\ldots \\
&= d_{n}+\ldots+d_{m-2}+d_{m-1}+\ldots \\
& \leq\left(M^{n}+\ldots+M^{m-2}+M^{m-1}+\ldots\right) d_{0} \\
&= M^{n}\left(I+M+\ldots+M^{n}+\ldots\right) d_{0}=M^{n}(I-M)^{-1} d_{0} .
\end{aligned}
$$

(notice that $I-M$ is non-singular due to $\rho(M)<1$ ). That implies

$$
d\left(g x_{m}, g x_{n}\right) \leq M^{n}(I-M)^{-1} d_{0} \text { and } d\left(g y_{m}, g y_{n}\right) \leq M^{n}(I-M)^{-1} d_{0},
$$

for all $m>n$.

Since $\rho(M)<1, M^{n}(I-M)^{-1} d_{0} \rightarrow \theta$ as $n \rightarrow \infty$. Therefore, $\left\{g x_{n}\right\}$ and $\left\{g y_{n}\right\}$ are Cauchy sequences. Since $X$ is a complete generalized metric space, there exist $x, y \in X$ such that

$$
\lim _{n \rightarrow \infty} g x_{n}=x \text { and } \lim _{n \rightarrow \infty} g y_{n}=y .
$$

Thus

$$
\lim _{n \rightarrow \infty} F\left(x_{n}, y_{n}\right)=\lim _{n \rightarrow \infty} g x_{n}=x \text { and } \lim _{n \rightarrow \infty} F\left(y_{n}, x_{n}\right)=\lim _{n \rightarrow \infty} g y_{n}=y .
$$

Since $\left\{g x_{n}\right\}$ and $\left\{g y_{n}\right\}$ are monotone, by the O-compatibility of $F$ and $g$, we have

$$
\lim _{n \rightarrow \infty} d\left(g F\left(x_{n}, y_{n}\right), F\left(g x_{n}, g y_{n}\right)\right)=0
$$

and

$$
\lim _{n \rightarrow \infty} d\left(g F\left(y_{n}, x_{n}\right), F\left(g y_{n}, g x_{n}\right)\right)=0 .
$$

Suppose (a) holds. Taking the limits as $n \rightarrow \infty$ in the following inequality

$$
d\left(g x, F\left(g x_{n}, g y_{n}\right)\right) \leq d\left(g x, g F\left(x_{n}, y_{n}\right)\right)+d\left(g F\left(x_{n}, y_{n}\right), F\left(g x_{n}, g y_{n}\right)\right)
$$

and using (9), (11) and the continuity of $F, g$, we get $d(g x, F(x, y)) \leq \theta$. This implies $g x=F(x, y)$.

Similarly, one has $g y=F(y, x)$.

Finally, suppose (b) holds. Since $\left\{g x_{n}\right\}$ is non-decreasing sequence and $g x_{n} \rightarrow$ 
$x$ and $\left\{g y_{n}\right\}$ is non-increasing sequence and $g y_{n} \rightarrow y$, by the assumption, we have $g g x_{n} \preceq g x$ and $g g y_{n} \succeq g y$ for all $n$. From (10), (11) and (12), we have

$$
\lim _{n \rightarrow \infty} F\left(g x_{n}, g y_{n}\right)=\lim _{n \rightarrow \infty} g F\left(x_{n}, y_{n}\right)=\lim _{n \rightarrow \infty} g g x_{n}=g x,
$$

and

$$
\lim _{n \rightarrow \infty} F\left(g y_{n}, g x_{n}\right)=\lim _{n \rightarrow \infty} g F\left(y_{n}, x_{n}\right)=\lim _{n \rightarrow \infty} g g y_{n}=g y .
$$

Since $g g y_{n} \preceq g y$ and $g g x_{n} \succeq g x$, we have

$$
\begin{aligned}
d(F(x, y), g x)+d(F(y, x), g y) \leq & d\left(F(x, y), F\left(g x_{n}, g y_{n}\right)\right)+d\left(F\left(g x_{n}, g y_{n}\right), g x\right) \\
& d\left(F(y, x), F\left(g y_{n}, g x_{n}\right)\right)+d\left(F\left(g y_{n}, g x_{n}\right), g y\right) \\
\leq \quad & d\left(F\left(g x_{n}, g y_{n}\right), g x\right)+d\left(F\left(g y_{n}, g x_{n}\right), g y\right) \\
& +A d\left(g x, g g x_{n}\right)+B d\left(g y, g g y_{n}\right) .
\end{aligned}
$$

Taking $n \rightarrow \infty$ in the previous inequality and using (13),(14), we get

$$
d(F(x, y), g x)+d(F(y, x), g y) \leq \theta .
$$

It implies $F(x, y)=g x$ and $F(y, x)=g y$. This completes the proof.

In Theorem 2.1, taking $g x=x$, for all $x \in X$, we obtain the following Corollary

Corollary 2.2. Let $(X, d, \preceq)$ be a partially ordered complete generalized metric space. Let $F: X \times X \rightarrow X$ be a mapping having the mixed monotone property on $X$ such that there exist two elements $x_{0}, y_{0} \in X$ with

$$
x_{0} \preceq F\left(x_{0}, y_{0}\right) \text { and } y_{0} \succeq F\left(y_{0}, x_{0}\right) .
$$

Assume that there exist $A, B \in M_{N}\left(\mathbb{R}_{+}\right)$with $\rho\left(\frac{1}{2}(A+B)\right)<1$ such that

$$
d(F(x, y), F(u, v))+d(F(y, x), F(v, u)) \leq A d(x, u)+B d(y, v),
$$

for all $x, y, u, v \in X$ with $x \succeq u$ and $y \preceq v$. Suppose either

(a) F is continuous or

(b) $X$ has the following property

(i) if a non-decreasing sequence $\left\{x_{n}\right\} \rightarrow x$, then $g x_{n} \preceq g x$ for all $n$,

(ii) if a non-increasing sequence $\left\{y_{n}\right\} \rightarrow y$, then gy $\preceq$ gyn for all $n$.

then $F$ has a coupled fixed point in $X$. 
In Theorem 2.1, taking $n=1$, we get the following Corollary

Corollary 2.3. Let $(X, d, \preceq)$ be a partially ordered complete metric space. Suppose $F: X \times X \rightarrow X$ and $g: X \rightarrow X$ are mappings such that $F$ has the mixed $g$-monotone property. Assume that there exist $a, b \in \mathbb{R}_{+}$with $a+b<2$ such that

$$
d(F(x, y), F(u, v))+d(F(y, x), F(v, u)) \leq a d(g x, g u)+b d(g y, g v),
$$

for all $x, y, u, v \in X$ with $g x \succeq g u$ and $g y \preceq g v$. Suppose $F(X \times X) \subseteq g(X)$, $g$ is continuous and $g$ is O-compatible with $F$. Suppose either

(a) F is continuous or

(b) $X$ has the following property

(i) if a non-decreasing sequence $\left\{x_{n}\right\} \rightarrow x$, then $g x_{n} \preceq$ gx for all $n$,

(ii) if a non-increasing sequence $\left\{y_{n}\right\} \rightarrow y$, then gy $\preceq g y_{n}$ for all $n$.

If there exists two elements $x_{0}, y_{0} \in X$ with

$$
g x_{0} \preceq F\left(x_{0}, y_{0}\right) \text { and } g y_{0} \succeq F\left(y_{0}, x_{0}\right) \text {, }
$$

then $F$ and $g$ have a coupled coincidence point in $X$.

Also, taking $n=1$ in Corollary 2.2, we get

Corollary 2.4. Let $(X, d, \preceq)$ be a partially ordered complete metric space. Let $F: X \times X \rightarrow X$ be a mapping having the mixed monotone property on $X$ such that there exist two elements $x_{0}, y_{0} \in X$ with

$$
x_{0} \preceq F\left(x_{0}, y_{0}\right) \quad \text { and } \quad y_{0} \succeq F\left(y_{0}, x_{0}\right) \text {. }
$$

Assume that there exist $a, b \in \mathbb{R}_{+}$with $a+b<2$ such that

$$
d(F(x, y), F(u, v))+d(F(y, x), F(v, u)) \leq a d(x, u)+b d(y, v)
$$

for all $x, y, u, v \in X$ with $x \succeq u$ and $y \preceq v$. Suppose either

(a) F is continuous or

(b) $X$ has the following property

(i) if a non-decreasing sequence $\left\{x_{n}\right\} \rightarrow x$, then $g x_{n} \preceq g x$ for all $n$,

(ii) if a non-increasing sequence $\left\{y_{n}\right\} \rightarrow y$, then gy $\preceq g y_{n}$ for all $n$. 
then $F$ has a coupled fixed point in $X$.

Remark 2.5. In Corollary 2.4, letting $a=b$, we get the result of Berinde (Theorem 1.11)

Now we shall prove the uniqueness of the coupled fixed point. Note that if $(X, \preceq)$ is a partially ordered set, then we endow the product $X \times X$ with the following partial order relation:

$$
\text { for }(x, y),(u, v) \in X \times X, \quad(x, y) \lesssim(u, v) \Longleftrightarrow x \preceq u, y \succeq v .
$$

Theorem 2.6. In addition to the hypotheses of Corollary 2.2, suppose that for every $(x, y),(z, t) \in X \times X$, there exists a $(u, v) \in X \times X$ that is comparable to $(x, y)$ and $(z, t)$, then $F$ has a unique coupled fixed point.

Proof. From Corollary 2.2 the set of coupled fixed points of $F$ is non-empty. Suppose $(x, y)$ and $(z, t)$ are coupled points of $F$, that is $x=F(x, y), y=$ $F(y, x), z=F(z, t)$ and $t=F(t, z)$, we shall show that $x=z$ and $y=t$.

By the assumption, there exists $(u, v) \in X \times X$ that is comparable to $(x, y)$ and $(z, t)$.

We define two following sequences $\left\{u_{n}\right\}$ and $\left\{v_{n}\right\}$ as follows

$$
u_{0}=u, v_{0}=v, u_{n+1}=F\left(u_{n}, v_{n}\right) \quad \text { and } \quad v_{n+1}=F\left(v_{n}, u_{n}\right), \quad \text { for all } n
$$

Since $(u, v)$ is comparable with $(x, y)$, we may assume that $(x, y) \gtrsim(u, v)=$ $\left(u_{0}, v_{0}\right)$. By using the mathematical induction and the mixed monotone property of $F$, it is easy to show that

$$
(x, y) \gtrsim\left(u_{n}, v_{n}\right), \text { for all } n .
$$

Since $x \succeq u_{n}$ and $y \preceq v_{n}$ for all $n$, from (15), we have

$$
\begin{aligned}
d\left(x, u_{n}\right)+d\left(y, v_{n}\right) & =d\left(F(x, y), F\left(u_{n-1}, v_{n-1}\right)\right)+d\left(F(y, x), F\left(v_{n-1}, u_{n-1}\right)\right) \\
& \leq A d\left(x, u_{n-1}\right)+B d\left(y, v_{n-1}\right) .
\end{aligned}
$$

Similarly,

$$
\begin{aligned}
d\left(v_{n}, y\right)+d\left(u_{n}, x\right) & =d\left(F\left(v_{n-1}, u_{n-1}\right), F(y, x)\right)+d\left(F\left(u_{n-1}, v_{n-1}\right), F(x, y)\right) \\
& \leq A d\left(v_{n-1}, y\right)+B d\left(u_{n-1}, x\right) .
\end{aligned}
$$

Therefore,

$$
\begin{aligned}
d\left(x, u_{n}\right)+d\left(y, v_{n}\right) \leq & \frac{1}{2}(A+B)\left(d\left(x, u_{n-1}\right)+d\left(y, v_{n-1}\right)\right) \\
= & M\left(d\left(x, u_{n-1}\right)+d\left(y, v_{n-1}\right)\right) \\
\leq & M^{2}\left(d\left(x, u_{n-2}\right)+d\left(y, v_{n-2}\right)\right) \\
& \cdots \\
\leq & M^{n}\left(d\left(x, u_{0}\right)+d\left(y, v_{0}\right)\right) .
\end{aligned}
$$


Since $M^{n} \rightarrow \Theta$ as $n \rightarrow \infty$, taking the limits in (19), we get

$$
\lim _{n \rightarrow \infty}\left[d\left(x, u_{n}\right)+d\left(y, v_{n}\right)\right]=\theta .
$$

That is

$$
\lim _{n \rightarrow \infty} d\left(x, u_{n}\right)=\lim _{n \rightarrow \infty} d\left(y, v_{n}\right)=\theta .
$$

Similarly,

$$
\lim _{n \rightarrow \infty} d\left(z, u_{n}\right)=\lim _{n \rightarrow \infty} d\left(t, v_{n}\right)=\theta .
$$

From (20) and (21), we have $x=z$ and $y=t$. The proof is complete

Theorem 2.7. In addition to the hypotheses of Corollary 2.2, suppose $x_{0}, y_{0}$ are comparable then $F$ has a fixed point, that is there exists $x \in X$ such that $F(x, x)=x$.

Proof. By Corollary 2.2, $F$ has a coupled fixed point $(x, y)$. We will show that $x=y$. Let us assume that $y_{0} \preceq x_{0}$. By the mathematical induction and the mixed monotone property of $F$, one can show that

$$
y_{n} \preceq x_{n}, \quad \text { for all } n \text {. }
$$

where $x_{n}=F\left(x_{n-1}, y_{n-1}\right), y_{n}=F\left(y_{n-1}, x_{n-1}\right), n=1,2,3, \ldots$.

Since $x_{n} \succeq y_{n}$,

$\left.d\left(F\left(x_{n}, y_{n}\right), F\left(y_{n}, x_{n}\right)\right)+d\left(F\left(y_{n}, x_{n}\right), F\left(x_{n}, y_{n}\right)\right) \leq A d\left(x_{n}, y_{n}\right)+B d\left(y_{n}, x_{n}\right)\right)$

or

$$
d\left(F\left(x_{n}, y_{n}\right), F\left(y_{n}, x_{n}\right)\right) \leq \frac{1}{2}(A+B) d\left(x_{n}, y_{n}\right)=M d\left(x_{n}, y_{n}\right) .
$$

By the triangle inequality,

$$
\begin{aligned}
d(x, y) & \leq d\left(x, x_{n+1}\right)+d\left(x_{n+1}, y_{n+1}\right)+d\left(y_{n+1}, y\right) \\
& =d\left(x, x_{n+1}\right)+d\left(y_{n+1}, y\right)+d\left(F\left(x_{n}, y_{n}\right), F\left(y_{n}, x_{n}\right)\right) \\
& \leq d\left(x, x_{n+1}\right)+d\left(y_{n+1}, y\right)+M d\left(x_{n}, y_{n}\right) .
\end{aligned}
$$

Taking $n \rightarrow \infty$ in the above inequality, we get $d(x, y)=\theta$. This implies $x=y$. The proof is concluded.

We next give two examples to illustrate our results.

Example 2.8. Let $X=\mathbb{R}$ with the generalized metric $d: X \times X \rightarrow \mathbb{R}^{2}$ be defined by

$$
d(x, y)=\left(\begin{array}{c}
|x-y| \\
2|x-y|
\end{array}\right), \text { for all } x, y \in X
$$


and the usual ordering $\leq$.

Let $F: X \times X \rightarrow X$ be defined by

$$
F(x, y)=\frac{1}{2} x-y, \text { for all } x, y \in X,
$$

and $g: X \rightarrow X$ be defined by

$$
g x=3 x, \text { for all } x \in X .
$$

Let $A, B \in M_{2}\left(\mathbb{R}_{+}\right)$with

$$
A=\left(\begin{array}{cc}
\frac{1}{3} & \frac{1}{3} \\
0 & \frac{1}{3}
\end{array}\right), \quad B=\left(\begin{array}{cc}
\frac{1}{6} & \frac{1}{6} \\
1 & \frac{1}{6}
\end{array}\right) .
$$

Then $X$ is complete, $F, g$ are continuous and $O$-compatible. $F(X \times X) \subseteq$ $g(X)$ and $F$ has the mixed $g$ - monotone property. $M=(A+B) / 2$ converges to zero and there exist $x_{0}=y_{0}=0$ such that $g x_{0} \leq F\left(x_{0}, y_{0}\right)$ and $g y_{0} \geq$ $F\left(y_{0}, x_{0}\right)$. Moreover, for $x, y, u, v \in X$ with $g x \geq g u, g y \leq g v$,i.e., $x \geq u, y \leq v$, we have

$$
\begin{aligned}
& d(F(x, y), F(u, v))=\left(\begin{array}{c}
\left|\frac{1}{2} x-y-\frac{1}{2} u+v\right| \\
|x-2 y-u+2 v|
\end{array}\right) \leq\left(\begin{array}{c}
\frac{1}{2}|x-u|+|y-v| \\
|x-u|+2|y-v|
\end{array}\right) \\
& d(F(y, x), F(v, u))=\left(\begin{array}{c}
\left|\frac{1}{2} y-x-\frac{1}{2} v+u\right| \\
|y-2 x-v+2 u|
\end{array}\right) \leq\left(\begin{array}{c}
\frac{1}{2}|y-v|+|x-u| \\
|y-v|+2|x-u|
\end{array}\right)
\end{aligned}
$$

Thus,

$$
d(F(x, y), F(u, v))+d(F(y, x), F(v, u)) \leq \frac{3}{2}\left(\begin{array}{c}
|x-u|+|y-v| \\
2|x-u|+2|y-v|
\end{array}\right)
$$

Also,

$$
\begin{aligned}
A d(g x, g u)+B d(g y, g v) & =\left(\begin{array}{cc}
\frac{1}{3} & \frac{1}{3} \\
0 & \frac{1}{3}
\end{array}\right)\left(\begin{array}{l}
3|x-u| \\
6|x-u|
\end{array}\right) \\
& +\left(\begin{array}{cc}
\frac{1}{6} & \frac{1}{6} \\
1 & \frac{1}{6}
\end{array}\right)\left(\begin{array}{l}
3|y-v| \\
6|y-v|
\end{array}\right) \\
& =\left(\begin{array}{c}
3|x-u|+\frac{3}{2}|y-v| \\
2|x-u|+4|y-v|
\end{array}\right) \\
& \geq d(F(x, y), F(u, v))+d(F(y, x), F(v, u)) .
\end{aligned}
$$

Therefore, all the conditions of Theorem 2.1 are satisfied. Applying Theorem 2.1 , we obtain that $F$ and $g$ have a coupled coincidence point. In fact, $(0,0)$ is the unique coupled coincidence point of $F$ and $g$. 
Example 2.9. Let $(X, d, \preceq), F$ and $g$ be defined as in Example 1.14.

Then:

(i) $X$ is complete and $X$ has the property

- if a non-decreasing sequence $\left\{x_{n}\right\} \rightarrow x$, then $g x_{n} \preceq g x$ for all $n$,

- if a non-increasing sequence $\left\{y_{n}\right\} \rightarrow y$, then $g y \preceq g y_{n}$ for all $n$.

(ii) $F(X \times X)=\{0,1\} \subset\{0\} \cup[1 / 2,1]=g(X)$.

(iii) $g$ is continuous and $g$ and $F$ are $O$-compatible.

(iv) There exist $x_{0}=0, y_{0}=1$ such that $g x_{0} \preceq F\left(x_{0}, y_{0}\right)$ and $g y_{0} \succeq F\left(y_{0}, x_{0}\right)$.

(v) $F$ has the mixed $g$-monotone property. Indeed, for every $y \in X$, let $x_{1}, x_{2} \in X$ such that $g x_{1} \preceq g x_{2}$

- if $g x_{1}=g x_{2}$ then $x_{1}, x_{2}=0$ or $x_{1}, x_{2} \in[1 / 2,1]$ or $x_{1}, x_{2} \in(1,3 / 2]$ or $x_{1}, x_{2} \in(3 / 2,2]$. Thus, $F\left(x_{1}, y\right)=0=F\left(x_{2}, y\right)$ if $y \in\{0\} \cup[1 / 2,1]$, and $x_{1}, x_{2}=0$ or $x_{1}, x_{2} \in[1 / 2,1]$, otherwise $F\left(x_{1}, y\right)=1=F\left(x_{2}, y\right)$.

- if $g x_{1} \prec g x_{2}$, then $g x_{1}=0$ and $g x_{2}=1$, i.e., $x_{1}=0$ and $x_{2} \in[1 / 2,1]$. Thus $F\left(x_{1}, y\right)=0=F\left(x_{2}, y\right)$ if $y \in\{0\} \cup[1 / 2,1]$, and $F\left(x_{1}, y\right)=1=$ $F\left(x_{2}, y\right)$ if $y \in(1,2]$.

Therefore, $F$ is the $g$ - non-decreasing in its first argument. Similarly, $F$ is the $g$ - non-increasing in its second argument. (vi) For $x, y, u, v \in X$, if $g x \succeq g u$ and $g y \preceq g v$ then $d(F(x, y), F(u, v))=0$. Indeed,

- if $g x \succ g u$ and $g y \prec g v$ then $y=u=0$ and $x, v \in[1 / 2,1]$. Thus $d(F(x, y), F(u, v))=d(0,0)=0$.

- if $g x=g u$ and $g y \prec g v$ then $y=0$ and $v \in[1 / 2,1]$. Thus if $x=$ $u=0$ or $x, u \in[1 / 2,1]$ then $d(F(x, y), F(u, v))=d(0,0)=0$, otherwise $d(F(x, y), F(u, v)=d(1,1)=0$. Similarly, if $g x \succ g u$ and $g y=g v$ then $d(F(x, y), F(u, v))=0$.

- if $g x=g u$ and $g y=g v$ then both $x, u$ are in one of the sets $\{0\}$, $[1 / 2,1],(1,3 / 2]$ or $(3 / 2,2]$ and both $y, v$ are also in one of the sets $\{0\}$, $[1 / 2,1],(1,3 / 2]$ or $(3 / 2,2]$. Thus $d(F(x, y), F(u, v))=d(0,0)=0$ if $x=u=0$ or $x, u \in[1 / 2,1]$ and $y=v=0$ or $y, v \in[1 / 2,1]$, otherwise, $d(F(x, y), F(u, v))=d(1,1)=0$.

Therefore, all the conditions of Corollary 2.3 are satisfied with $a, b \geq 0$ and $a+b<2$. Applying Corollary 2.3, we conclude that $F$ and $g$ have a coupled coincidence point.

Note that, we cannot apply the result of Choudhury and Kundu [10] as well as the result of Lakshmikantham and Círíc [18] to this example. 


\section{Application to integro-differential equations}

In this section, we use the results that are established in Section 2 to derive some results on the existence and uniqueness of solutions of integro-differential equations.

Consider the integro-differential equation

$$
x(t)=\int_{0}^{t}\left(f\left(s, x(s), x^{\prime}(s)\right)+g\left(s, x(s), x^{\prime}(s)\right)\right) d s \text { for all } t \in[0, T],
$$

for some $T>0$.

We consider the following conditions

(H1) $f, g \in C([0, T] \times \mathbb{R} \times \mathbb{R}, \mathbb{R})$.

(H2) There exist $\alpha, \beta, \lambda, \mu>0$ such that

$$
0 \leq f(t, x, y)-f(t, u, v) \leq \alpha(x-u)+\beta(y-v),
$$

and

$$
-\lambda(x-u)-\mu(y-v) \leq g(t, x, y)-g(t, u, v) \leq 0,
$$

for all $t \in[0, T], x, y, u, v \in \mathbb{R}$ with $x \geq u, y \geq v$.

Definition 3.1. An element $(\omega, \vartheta) \in C([0, T], \mathbb{R}) \times C([0, T], \mathbb{R})$ is called a coupled lower and upper solution of the integro-differential equation (24) if $\omega(0)=\vartheta(0)=0$ and

$$
\begin{aligned}
\omega^{\prime}(t) & \leq f\left(t, \omega(t), \omega^{\prime}(t)\right)+g\left(t, \vartheta(t), \vartheta^{\prime}(t)\right) \\
& \leq f\left(t, \vartheta(t), \vartheta^{\prime}(t)\right)+g\left(t, \omega(t), \omega^{\prime}(t)\right) \leq \vartheta^{\prime}(t),
\end{aligned}
$$

for all $t \in[0, T]$.

Theorem 3.2. With the assumptions (H1)-(H2). If the integro-differential equation (24) has a coupled lower and upper solution and $T(\alpha+\lambda)+\beta+\mu<1$ then it has a unique solution in $C([0, T], \mathbb{R})$.

Proof. Set $y(t)=x^{\prime}(t)$, from equation (24), we have the following system equations

$$
\left\{\begin{array}{l}
x(t)=\int_{0}^{t}(f(s, x(s), y(s))+g(s, x(s), y(s))) d s \\
y(t)=f(t, x(t), y(t))+g(t, x(t), y(t))
\end{array}\right.
$$


for all $t \in[0, T]$.

Set $X=C([0, T], R) \times C([0, T], R)$. Then $X$ is a partially ordered set if we define the following order relation on $X$ :

$(x, y),(u, v) \in X,(x, y) \preceq(u, v) \Leftrightarrow x(t) \leq u(t), y(t) \leq v(t)$, for all $t \in[0, T]$.

Also, $(X, d)$ is a complete generalized metric space with metric

$$
d((x, y),(u, v))=(\|x-u\|,\|y-v\|) .
$$

for all $(x, y),(u, v) \in X$, where $\|x\|=\max \{|x(t)|: t \in[0, T]\}$ for all $x$ in $C([0, T], \mathbb{R})$.

Obviously, if $\left\{\left(x_{n}, y_{n}\right)\right\}$ is a monotone non-decreasing sequence in $X$ which converges to $(x, y)$ in $X$ and $\left\{\left(u_{n}, v_{n}\right)\right\}$ is a monotone non-increasing sequence in $X$ which converges to $(u, v)$ in $X$, then $\left(x_{n}, y_{n}\right) \preceq(x, y)$ and $(u, v) \preceq\left(u_{n}, v_{n}\right)$ for all $n$. Also, $X \times X$ is a partially ordered set if we define the following order relation on $X \times X$ : for $\left(\left(x_{1}, y_{1}\right),\left(u_{1}, v_{1}\right)\right),\left(\left(x_{2}, y_{2}\right),\left(u_{2}, v_{2}\right)\right) \in X \times X$,

$\left(\left(x_{1}, y_{1}\right),\left(u_{1}, v_{1}\right)\right) \lesssim\left(\left(x_{2}, y_{2}\right),\left(u_{2}, v_{2}\right)\right) \Leftrightarrow\left(x_{1}, y_{1}\right) \preceq\left(x_{2}, y_{2}\right),\left(u_{2}, v_{2}\right) \preceq\left(u_{1}, v_{1}\right)$

For any $(x, y),(u, v) \in X$, then $(\max \{x, u\}, \max \{y, v\})$ and $(\min \{x, u\}, \min \{y, v\})$ are in $X$ and are a upper and a lower bound of $(x, y),(u, v)$, respectively. Therefore, for every $\left(\left(x_{1}, y_{1}\right),\left(u_{1}, v_{1}\right)\right)$, $\left(\left(x_{2}, y_{2}\right),\left(u_{2}, v_{2}\right)\right) \in X \times X$, there exists a

$$
\left(\left(\max \left\{x_{1}, x_{2}\right\}, \max \left\{y_{1}, y_{2}\right\}\right),\left(\min \left\{u_{1}, u_{2}\right\}, \min \left\{v_{1}, v_{2}\right\}\right)\right) \in X \times X,
$$

which is comparable to $\left(\left(x_{1}, y_{1}\right),\left(u_{1}, v_{1}\right)\right)$ and $\left(\left(x_{2}, y_{2}\right),\left(u_{2}, v_{2}\right)\right)$.

We define a mapping $F: X \times X \rightarrow X$ as follows

$$
F((x, y),(u, v))=\left(F_{1}((x, y),(u, v)), F_{2}((x, y),(u, v))\right)
$$

where $F_{1}, F_{2}: X \times X \rightarrow C([0, T], \mathbb{R})$ are defined by

$$
F_{1}((x, y),(u, v))(t)=\int_{0}^{t}(f(s, x(s), y(s))+g(s, u(s), v(s))) d s,
$$

and

$$
F_{2}((x, y),(u, v))(t)=f(t, x(t), y(t))+g(t, u(t), v(t)),
$$

for all $x, y, u, v \in C([0, T], \mathbb{R})$, and for all $t \in[0, T]$.

We claim that $F$ has the mixed monotone property. In fact, for any $(x, y)$ and $(u, v)$ in $X$, if $\left(x_{1}, y_{1}\right) \preceq\left(x_{2}, y_{2}\right)$, we have 


$$
\begin{aligned}
F_{1}\left(\left(x_{1}, y_{1}\right),(u, v)\right) & (t)-F_{1}\left(\left(x_{2}, y_{2}\right),(u, v)\right)(t) \\
= & \int_{0}^{t}\left(f\left(s, x_{1}(s), y_{1}(s)\right)+g(s, u(s), v(s))\right) d s \\
& -\int_{0}^{t}\left(f\left(s, x_{2}(s), y_{2}(s)\right)+g(s, u(s), v(s))\right) d s \\
& =\int_{0}^{t}\left(f\left(s, x_{1}(s), y_{1}(s)\right)-f\left(s, x_{2}(s), y_{2}(s)\right)\right) d s \leq 0,
\end{aligned}
$$

and

$$
\begin{aligned}
& F_{2}(\left.\left(x_{1}, y_{1}\right),(u, v)\right)(t)-F_{2}\left(\left(x_{2}, y_{2}\right),(u, v)\right)(t) \\
&= f\left(t, x_{1}(t), y_{1}(t)\right)+g(t, u(t), v(t))-\left(f\left(t, x_{2}(t), y_{2}(t)\right)+g(t, u(t), v(t))\right) \\
&\quad \quad \quad \text { by the assumption }(\mathrm{H} 2)) \\
&=\quad f\left(t, x_{1}(t), y_{1}(t)\right)-f\left(t, x_{2}(t), y_{2}(t)\right) \leq 0 .
\end{aligned}
$$

Therefore, $F\left(\left(x_{1}, y_{1}\right),(u, v)\right) \preceq F\left(\left(x_{2}, y_{2}\right),(u, v)\right)$ that is, $F$ is non-deacreasing in the first argument.

Similarly, if $\left(u_{1}, v_{1}\right) \preceq\left(u_{2}, v_{2}\right)$ then we have

$$
\begin{aligned}
F_{1}\left((x, y),\left(u_{1}, v_{1}\right)\right) & (t)-F_{1}\left((x, y),\left(u_{2}, v_{2}\right)\right)(t) \\
= & \int_{0}^{t}\left(f(s, x(s), y(s))+g\left(s, u_{1}(s), v_{1}(s)\right)\right) d s \\
& -\int_{0}^{t}\left(f(s, x(s), y(s))+g\left(s, u_{2}(s), v_{2}(s)\right)\right) d s \\
& =\int_{0}^{t}\left(g\left(s, u_{1}(s), v_{1}(s)\right)-g\left(s, u_{2}(s), v_{2}(s)\right)\right) d s \geq 0,
\end{aligned}
$$

and 


$$
\begin{aligned}
& F_{2}\left((x, y),\left(u_{1}, v_{1}\right)\right)(t)-F_{2}\left((x, y),\left(u_{2}, v_{2}\right)\right)(t) \\
&= f(s, x(s), y(s))+g\left(s, u_{1}(s), v_{1}(s)\right)-\left(f(s, x(s), y(s))+g\left(s, u_{2}(s), v_{2}(s)\right)\right) \\
& \quad\quad \text { by the assumption }(\mathrm{H} 2)) \\
&= g\left(s, u_{1}(s), v_{1}(s)\right)-f\left(s, u_{2}(s), v_{2}(s)\right) \geq 0 .
\end{aligned}
$$

Therefore, $F\left((x, y),\left(u_{1}, v_{1}\right)\right) \succeq F\left((x, y),\left(u_{2}, v_{2}\right)\right)$, that is, $F$ is non-increasing in the second argument.

The claim is proved.

Now for any $\left(x_{1}, y_{1}\right),\left(x_{2}, y_{2}\right),\left(u_{1}, v_{1}\right),\left(u_{2}, v_{2}\right) \in X$ with $\left(x_{1}, y_{1}\right) \succeq\left(x_{2}, y_{2}\right)$ and $\left(u_{1}, v_{1}\right) \preceq\left(u_{2}, v_{2}\right)$, we have,

$$
\begin{aligned}
\left|F_{1}\left(\left(x_{1}, y_{1}\right),\left(u_{1}, v_{1}\right)\right)(t)-F_{1}\left(\left(x_{2}, y_{2}\right),\left(u_{2}, v_{2}\right)\right)(t)\right| & || \int_{0}^{t}\left(f\left(s, x_{1}(s), y_{1}(s)\right)+g\left(s, u_{1}(s), v_{1}(s)\right)\right) d s \\
= & -\int_{0}^{t}\left(f\left(s, x_{2}(s), y_{2}(s)\right)+g\left(s, u_{2}(s), v_{2}(s)\right)\right) d s \mid \\
= & \mid \int_{0}^{t}\left(f\left(s, x_{1}(s), y_{1}(s)\right)-f\left(s, x_{2}(s), y_{2}(s)\right)\right) d s \\
& -\int_{0}^{t}\left(g\left(s, u_{1}(s), v_{1}(s)\right)-g\left(s, u_{2}(s), v_{2}(s)\right)\right) d s \mid \\
\leq & \int_{0}^{t}\left(\alpha\left(x_{1}(s)-x_{2}(s)\right)+\beta\left(y_{1}(s)-y_{2}(s)\right)\right) d s \\
& +\int_{0}^{t}\left(\lambda\left(u_{2}(s)-u_{1}(s)\right)+\mu\left(v_{2}(s)-v_{1}(s)\right)\right) d s \\
\leq & \alpha T\left\|x_{1}-x_{2}\right\|+\beta T\left\|y_{1}-y_{2}\right\|+\lambda T\left\|u_{2}-u_{1}\right\|+\mu T\left\|v_{2}-v_{1}\right\|
\end{aligned}
$$

Therefore,

$$
\begin{aligned}
d\left(F_{1}\left(\left(x_{1}, y_{1}\right),\left(u_{1}, v_{1}\right)\right), F_{1}\left(\left(x_{2}, y_{2}\right),\left(u_{2}, v_{2}\right)\right)\right) \leq & \alpha T\left\|x_{1}-x_{2}\right\|+\beta T\left\|y_{1}-y_{2}\right\| \\
& +\lambda T\left\|u_{1}-u_{2}\right\|+\mu T\left\|v_{1}-v_{2}\right\| .
\end{aligned}
$$

Similarly, we have

$$
\begin{aligned}
d\left(F_{1}\left(\left(u_{2}, v_{2}\right),\left(x_{2}, y_{2}\right)\right), F_{1}\left(\left(u_{1}, v_{1}\right),\left(x_{1}, y_{1}\right)\right)\right) \leq & \alpha T\left\|u_{2}-u_{1}\right\|+\beta T\left\|v_{2}-v_{1}\right\| \\
& +\lambda T\left\|x_{1}-x_{2}\right\|+\mu T\left\|y_{1}-y_{2}\right\| .
\end{aligned}
$$


On the other hand, for $\left(x_{1}, y_{1}\right),\left(x_{2}, y_{2}\right),\left(u_{1}, v_{1}\right),\left(u_{2}, v_{2}\right) \in X$ with $\left(x_{1}, y_{1}\right) \succeq$ $\left(x_{2}, y_{2}\right),\left(u_{1}, v_{1}\right) \preceq\left(u_{2}, v_{2}\right)$, we also have

$$
\begin{aligned}
& \left|F_{2}\left(\left(x_{1}, y_{1}\right),\left(u_{1}, v_{1}\right)\right)(t)-F_{2}\left(\left(x_{2}, y_{2}\right),\left(u_{2}, v_{2}\right)\right)(t)\right| \\
& \quad=\left|f\left(t, x_{1}(t), y_{1}(t)\right)+g\left(t, u_{1}(t), v_{1}(t)\right)-\left(f\left(t, x_{2}(t), y_{2}(t)\right)+g\left(t, u_{2}(t), v_{2}(t)\right)\right)\right| \\
& \quad=\left|\left(f\left(t, x_{1}(t), y_{1}(t)\right)-f\left(t, x_{2}(t), y_{2}(t)\right)\right)+\left(g\left(t, u_{1}(t), v_{1}(t)\right)-g\left(t, u_{2}(t), v_{2}(t)\right)\right)\right| \\
& \quad \leq \alpha\left(x_{1}(t)-x_{2}(t)\right)+\beta\left(y_{1}(t)-y_{2}(t)\right)+\lambda\left(u_{2}(t)-u_{1}(t)\right)+\mu\left(v_{2}(t)-v_{1}(t)\right) .
\end{aligned}
$$

Thus,

$$
\begin{aligned}
d\left(F_{2}\left(\left(x_{1}, y_{1}\right),\left(u_{1}, v_{1}\right)\right), F_{2}\left(\left(x_{2}, y_{2}\right),\left(u_{2}, v_{2}\right)\right)\right) \leq & \alpha\left\|x_{1}-x_{2}\right\|+\beta\left\|y_{1}-y_{2}\right\| \\
& +\lambda\left\|u_{2}-u_{1}\right\|+\mu\left\|v_{2}-v_{1}\right\| .
\end{aligned}
$$

Similarly,

$$
\begin{aligned}
d\left(F_{2}\left(\left(u_{2}, v_{2}\right),\left(x_{2}, y_{2}\right)\right), F_{2}\left(\left(u_{1}, v_{1}\right),\left(x_{1}, y_{1}\right)\right)\right) \leq & \alpha\left\|u_{2}-u_{1}\right\|+\beta\left\|v_{2}-v_{1}\right\| \\
& +\lambda\left\|x_{1}-x_{2}\right\|+\mu\left\|y_{1}-y_{2}\right\| .
\end{aligned}
$$

Therefore, for any $\left(x_{1}, y_{1}\right),\left(x_{2}, y_{2}\right),\left(u_{1}, v_{1}\right),\left(u_{2}, v_{2}\right) \in X$ with $\left(x_{1}, y_{1}\right) \succeq$ $\left(x_{2}, y_{2}\right),\left(u_{1}, v_{1}\right) \preceq\left(u_{2}, v_{2}\right)$, we have

$$
\begin{aligned}
d\left(F\left(\left(x_{1}, y_{1}\right),\left(u_{1}, v_{1}\right)\right), F\left(\left(x_{2}, y_{2}\right),\left(u_{2}, v_{2}\right)\right)\right) & +d\left(F\left(\left(u_{1}, v_{1}\right),\left(x_{1}, y_{1}\right)\right), F\left(\left(u_{2}, v_{2}\right),\left(x_{2}, y_{2}\right)\right)\right) \\
= & d\left(F\left(\left(x_{1}, y_{1}\right),\left(u_{1}, v_{1}\right)\right), F\left(\left(x_{2}, y_{2}\right),\left(u_{2}, v_{2}\right)\right)\right) \\
& +d\left(F\left(\left(u_{2}, v_{2}\right),\left(x_{2}, y_{2}\right)\right), F\left(\left(u_{1}, v_{1}\right),\left(x_{1}, y_{1}\right)\right)\right) \\
= & \left(\begin{array}{c}
d\left(F_{1}\left(\left(x_{1}, y_{1}\right),\left(u_{1}, v_{1}\right)\right), F_{1}\left(\left(x_{2}, y_{2}\right),\left(u_{2}, v_{2}\right)\right)\right) \\
d\left(F_{2}\left(\left(x_{1}, y_{1}\right),\left(u_{1}, v_{1}\right)\right), F_{2}\left(\left(x_{2}, y_{2}\right),\left(u_{2}, v_{2}\right)\right)\right)
\end{array}\right) \\
& +\left(\begin{array}{c}
d\left(F_{1}\left(\left(u_{2}, v_{2}\right),\left(x_{2}, y_{2}\right)\right), F_{1}\left(\left(u_{1}, v_{1}\right),\left(x_{1}, y_{1}\right)\right)\right) \\
d\left(F_{2}\left(\left(u_{2}, v_{2}\right),\left(x_{2}, y_{2}\right)\right), F_{2}\left(\left(u_{1}, v_{1}\right),\left(x_{1}, y_{1}\right)\right)\right)
\end{array}\right) \\
\leq & \left(\begin{array}{c}
(T \alpha+T \lambda)\left(\left\|x_{1}-x_{2}\right\|+\left\|u_{1}-u_{2}\right\|\right) \\
(\alpha+\lambda)\left(\left\|x_{1}-x_{2}\right\|+\left\|u_{1}-u_{2}\right\|\right)
\end{array}\right) \\
& +\left(\begin{array}{c}
(T \beta+T \mu)\left(\left\|y_{1}-y_{2}\right\|+\left\|v_{1}-v_{2}\right\|\right) \\
(\beta+\mu)\left(\left\|y_{1}-y_{2}\right\|+\left\|v_{1}-v_{2}\right\|\right)
\end{array}\right) \\
= & \left(\begin{array}{c}
T \alpha+T \lambda T \beta+T \mu \\
\alpha+\lambda
\end{array}\right)\left(\begin{array}{c}
\alpha x_{1}-x_{2}\|+\| u_{1}-u_{2} \| \\
\left\|y_{1}-y_{2}\right\|+\left\|v_{1}-v_{2}\right\|
\end{array}\right) \\
= & A\left[\begin{array}{c}
\left.\left.d\left(x_{1}, y_{1}\right),\left(x_{2}, y_{2}\right)\right)+d\left(\left(u_{1}, v_{1}\right),\left(u_{2}, v_{2}\right)\right)\right],
\end{array}\right)
\end{aligned}
$$

where

$$
A=\left(\begin{array}{cc}
T \alpha+T \lambda & T \beta+T \mu \\
\alpha+\lambda & \beta+\mu
\end{array}\right)
$$


It is easy to see that the matrix $A$ has two eigenvalues $\delta_{1}=0$ and $\delta_{2}=$ $T(\alpha+\lambda)+\beta+\mu<1$. Hence $A$ converges to zero.

Thus $F$ verifies the contraction condition (15) in Corollary (2.2) with $A=B$. Now let $\left(\omega_{1}, \vartheta_{1}\right)$ be a coupled lower and upper solution of the equation (24), then we have

$$
\begin{aligned}
\omega_{1}{ }^{\prime}(t) & \leq f\left(t, \omega_{1}(t), \omega_{1}{ }^{\prime}(t)\right)+g\left(t, \vartheta_{1}(t), \vartheta_{1}{ }^{\prime}(t)\right) \\
& \leq f\left(t, \vartheta_{1}(t), \vartheta_{1}{ }^{\prime}(t)\right)+g\left(t, \omega_{1}(t), \omega_{1}{ }^{\prime}(t)\right) \leq \vartheta_{1}{ }^{\prime}(t),
\end{aligned}
$$

for all $t \in[0, T]$ and $\omega_{1}(0)=\vartheta_{1}(0)=0$.

Set $\omega_{2}(t)=\omega_{1}^{\prime}(t)$ and $\vartheta_{2}(t)=\vartheta_{1}(t)^{\prime}$ for all $t \in[0, T]$. From (26), for all $t \in[0, T]$, we have

$$
\begin{aligned}
\omega_{2}(t) & \leq f\left(t, \omega_{1}(t), \omega_{2}(t)\right)+g\left(t, \vartheta_{1}(t), \vartheta_{2}(t)\right) \\
& \leq f\left(t, \vartheta_{1}(t), \vartheta_{2}(t)\right)+g\left(t, \omega_{1}(t), \omega_{2}(t)\right) \leq \vartheta_{2}(t),
\end{aligned}
$$

that is, for all $t \in[0, T]$,

$$
\omega_{2}(t) \leq F_{2}\left(\left(\omega_{1}, \omega_{2}\right),\left(\vartheta_{1}, \vartheta_{2}\right)\right)(t) \leq F_{2}\left(\left(\vartheta_{1}, \vartheta_{2}\right),\left(\omega_{1}, \omega_{2}\right)\right)(t) \leq \vartheta_{2}(t) .
$$

Also, by (26), for all $t \in[0, T]$, we have

$$
\begin{aligned}
\int_{0}^{t} \omega_{1}{ }^{\prime}(s) d s & \leq \int_{0}^{t}\left(f\left(s, \omega_{1}(s), \omega_{1}{ }^{\prime}(s)\right)+g\left(t, \vartheta_{1}(s), \vartheta_{1}{ }^{\prime}(t)\right)\right) d s \\
& \leq \int_{0}^{t}\left(f\left(s, \vartheta_{1}(s), \vartheta_{1}{ }^{\prime}(s)\right)+g\left(s, \omega_{1}(s), \omega_{1}{ }^{\prime}(s)\right)\right) d s \leq \int_{0}^{t} \vartheta_{1}{ }^{\prime}(s) d s
\end{aligned}
$$

or

$$
\begin{aligned}
\omega_{1}(t)-\omega_{1}(0) & \leq \int_{0}^{t}\left(f\left(s, \omega_{1}(s), \omega_{2}(s)\right)+g\left(t, \vartheta_{1}(s), \vartheta_{2}(s)\right)\right) d s \\
& \leq \int_{0}^{t}\left(f\left(s, \vartheta_{1}(s), \vartheta_{2}(s)\right)+g\left(s, \omega_{1}(s), \omega_{2}(s)\right)\right) d s \leq \vartheta_{1}(t)-\vartheta_{1}(0)
\end{aligned}
$$

From (28) and the fact that $\omega_{1}(0)=\vartheta(0)=0$, we get

$$
\omega_{1}(t) \leq F_{1}\left(\left(\omega_{1}, \omega_{2}\right),\left(\vartheta_{1}, \vartheta_{2}\right)\right)(t) \leq F_{1}\left(\left(\vartheta_{1}, \vartheta_{2}\right),\left(\omega_{1}, \omega_{2}\right)\right)(t) \leq \vartheta_{1}(t) .
$$

From (27) and (29), we have

$$
\begin{aligned}
\left(\omega_{1}, \omega_{2}\right) & \leq\left(F_{1}\left(\left(\omega_{1}, \omega_{2}\right),\left(\vartheta_{1}, \vartheta_{2}\right)\right), F_{2}\left(\left(\omega_{1}, \omega_{2}\right),\left(\vartheta_{1}, \vartheta_{2}\right)\right)\right) \\
& \leq\left(F_{1}\left(\left(\vartheta_{1}, \vartheta_{2}\right),\left(\omega_{1}, \omega_{2}\right)\right), F_{2}\left(\left(\vartheta_{1}, \vartheta_{2}\right),\left(\omega_{1}, \omega_{2}\right)\right)\right) \leq\left(\vartheta_{1}, \vartheta_{2}\right)
\end{aligned}
$$


This means that there exist $\left(\omega_{1}, \omega_{2}\right),\left(\vartheta_{1}, \vartheta_{2}\right) \in X$ such that

$$
\left(\omega_{1}, \omega_{2}\right) \preceq F\left(\left(\omega_{1}, \omega_{2}\right),\left(\vartheta_{1}, \vartheta_{2}\right)\right) \text { and }\left(\vartheta_{1}, \vartheta_{2}\right) \succeq F\left(\left(\vartheta_{1}, \vartheta_{2}\right),\left(\omega_{1}, \omega_{2}\right)\right) \text {. }
$$

Thus all the conditions of Theorem 2.6 are satisfied. Applying this theorem, $F$ has a unique coupled fixed point $\left(x^{*}, y^{*}\right),\left(u^{*}, v^{*}\right)$ in $X \times X$. Since $\left(\omega_{1}, \omega_{2}\right) \preceq$ $\left(\vartheta_{1}, \vartheta_{2}\right)$, applying Theorem 2.7 , we conclude that $\left(x^{*}, y^{*}\right)=\left(u^{*}, v^{*}\right)$ is the unique fixed point of $F$. It means the system of equations (25) has the unique solution $\left(x^{*}(t), y^{*}(t)\right)$. That means

$$
\left\{\begin{array}{l}
x^{*}(t)=\int_{0}^{t}\left(f\left(s, x^{*}(s), y^{*}(s)\right)+g\left(s, x^{*}(s), y^{*}(s)\right)\right) d s \\
y^{*}(t)=f\left(t, x^{*}(t), y^{*}(t)\right)+g\left(t, x^{*}(t), y^{*}(t)\right)
\end{array}, \quad \text { for all } t \in[0, T] .\right.
$$

The first equality shows that $x^{*} \in C([0, T], \mathbb{R})$ and after taking the derivative that equation, we have

$$
\left(x^{*}\right)^{\prime}(t)=f\left(t, x^{*}(t), y^{*}(t)\right)+g\left(t, x^{*}(t), y^{*}(t)\right)=y^{*}(t) .
$$

Therefore $x^{*} \in C([0, T], \mathbb{R})$ is the unique solution of the equation (24). The proof is complete.

\section{References}

[1] R.P. Agarwal, M.A. El-Gebeily, D. O'Regan, Generalized contractions in partially ordered metric spaces, Appl. Anal.87 (2008) 109-116.

[2] A. Amini-Harandi , H. Emami, A fixed point theorem for contraction type maps in partially ordered metric spaces and application to ordinary differential equations, Nonlinear Analysis 72 (2010) 2238 -2242.

[3] I. Altun, H. Simsek, Some fixed point theorems on ordered metric spaces and application, Fixed Point Theory Appl. 2010 (2010) 17 pages. Article ID 621469 .

[4] H. Aydi, B. Damjanović, B. Samet, W. Shatanawi Coupled fixed point theorems for nonlinear contractions in partially ordered $G$-metric spaces, Math. Comput. Modelling, 54 (2011) 2443-2450.

[5] V. Berinde, Generalized coupled fixed point theorems for mixed monotone mappings in partially ordered metric spaces, Nonlinear Anal. TMA $\mathbf{7 4}$ (2011) 7347-7355. 
[6] T. G. Bhaskar, V. Lakshmikantham, Fixed point theorems in partially orderedmetric spaces and applications, Nonlinear Anal. 65 (2006) 13791393.

[7] A. Bica, S. Muresan, Periodic solutions for a delay integro-differential equations in biomathematics, RGMIA Res. Report Coll, 6 (2003), 755761.

[8] A. Bica, S. Muresan, Applications of the Perovs fixed point theorem to delay integro-differential equations, Chap. 3 in Fixed Point Theory and Applications (Y.J. Cho, et al., Eds), Vol. 7, Nova Science Publishers Inc., New York, 2006.

[9] A. Bucur, L. Guran, A. Petrusel, Fixed points for multivalued operators on a set endowed with vector-valued metrics and applications, Fixed Point Theory, 10 (2009) 19-34.

[10] B. S. Choudhury, A. Kundu, A coupled coincidence point result in partially ordered metric spaces for compatible mappings, Nonlinear Analysis 73 (2010) 2524-2531.

[11] B.S. Choudhury and P. Maity, Coupled fixed point results in generalized metric spaces, Math. Comput. Modelling, 54 (2011) 73-79.

[12] L. Círíc, N. Cakić, M. Rajović, J.S. Ume, Monotone generalized nonlinear contractions in partially ordered metric spaces, Fixed Point Theory Appl. 2008 (2008) 11 pages. Article ID 131294.

[13] A. D. Filip, A. Petrusel, Fixed point theorems on spaces endowed with vector-valued metrics, Fixed Point Theory and Applications, Vol. 2010, Article ID 281381, 15 pp.

[14] J. Harjani, B. Lopez, K. Sadarangani, Fixed point theorems for mixed monotone operators and applications to integral equations, Nonlinear Anal. 74 (2011) 1749-1760.

[15] J. Harjani, K. Sadarangani, Fixed point theorems for weakly contractive mappings in partially ordered sets, Nonlinear Anal. 71 (2009) 3403 -3410.

[16] S. Hong, Fixed points of multivalued operators in ordered metric spaces with applications, Nonlinear Analysis, 72 (2010) 3929-3942.

[17] E. Karapnar, Couple fixed point theorems for nonlinear contractions in cone metric spaces. Comput. Math. Appl. 59 (2010), 3656-3668. 
COUPLED POINTS IN ORDERED GENERALIZED METRIC SPACES AND

[18] V. Lakshmikantham, L. Círíc, Coupled fixed point theorems for nonlinear contractions in partially ordered metric spaces, Nonlinear Anal. 70 (2009) 4341- 4349 .

[19] N. V. Luong, N. X. Thuan, Coupled fixed points in partially ordered metric spaces and application, Nonlinear Anal. 74 (2011) 983-992.

[20] N. V. Luong, N. X. Thuan. Coupled fixed point theorems for mixed monotone mappings and application to nonlinear integral equations. Comput. Math. Appl. 62 (2011) 4238 - 4248

[21] J.J. Nieto, R.L. Pouso, R. Rodríguez - López, Fixed point theorems in ordered abstract sets, Proc. Amer. Math. Soc. 135 (2007) 2505 -2517.

[22] J.J. Nieto, R. Rodríguez -López, Contractive mapping theorems in partially ordered sets and applications to ordinary differential equations, Order 22 (2005) 223 - 239.

[23] J.J. Nieto, R. Rodríguez -López, Existence and uniqueness of fixed point in partially ordered sets and applications to ordinary differential equations, Acta Math. Sin. 23 (2007) 2205- 2212.

[24] D. O'Regan, A. Petrusel, Fixed point theorems for generalized contractions in ordered metric spaces, J. Math. Anal. Appl. 341 (2008) 1241 -1252 .

[25] D. O'Regan, R. Precup, Continuation theory for contractions on spaces with two vector-valued metrics, Applicable Analysis, 82 (2003), 131-144.

[26] D. O'Regan, N. Shahzad, R. P. Agarwal, Fixed point theory for generalized contractive maps on spaces with vector-valued metrics, in Fixed Point Theory and Applications. Vol. 6, pp. 143149, Nova Science, New York, NY, USA, 2007.

[27] A. Petrusel, I.A. Rus, Fixed point theorems in ordered L-spaces, Proc. Amer. Math. Soc. 134 (2006) 411- 418.

[28] A. I. Perov, On the Cauchy problem for a system of ordinary differential equations, Pviblizhen. Met. Reshen. Differ. Uvavn., 2 (1964) 115134.

[29] A.I. Perov, A.V. Kibenko, On a general method to study the boundary value problems, Iz. Acad. Nauk., 30 (1966), 249-264.

[30] R. Precup, The role of matrices that are convergent to zero in the study of semi linear operator systems, Mathematical and Computer Modeling, 49 (2009) 703-708. 
[31] M. Turinici, Finite-dimensional vector contractions and their fixed points, Studia Universitatis Babes Bolyai. Mathematica, 35 (2009), 30-42.

[32] I. A. Rus, Principles and applications of the fixed point theory, Dacia, Cluj-Napoca, Romania, 1979.

[33] A.C.M. Ran, M.C.B. Reurings, A fixed point theorem in partially ordered sets and some applications to matrix equations, Proc. Amer. Math. Soc. 132 (2004) $1435-1443$.

[34] B. Samet, Coupled fixed point theorems for a generalized Meir-Keeler contraction in partially ordered metric spaces, Nonlinear Anal 72 (2010) 4508-4517.

[35] W. Shatanawi, Partially ordered cone metric spaces and coupled fixed point results. Comput. Math. Appl. 60 (2010) 2508-2515.

[36] W. Shatanawi, B. Samet, M. Abbas, Coupled fixed point theorems for mixed monotone mappings in ordered partial metric spaces, Mathematical and Computer Modelling. 55 (2012) 680-687.

[37] R. S. Varga, Matrix Iterative Analysis, vol. 27 of Springer Series in Computational Mathematics, Springer, Berlin, Germany, 2000.

[38] F. Voicu, Fixed-point theorems in vector metric spaces, Studia Universitatis Babes Bolyai. Mathematica, 36 (1991) 53-56 (French).

Nguyen Van Luong,

Department of Natural Sciences,

Hong Duc University, Thanh Hoa, Vietnam.

Email: luonghdu@gmail.com

Nguyen Xuan Thuan,

Department of Natural Sciences,

Hong Duc University, Thanh Hoa, Vietnam.

Email: thuannx7@gmail.com 